\title{
The physiological function of periplasmic glucose oxidation in phosphate-limited chemostat cultures of Klebsiella pneumoniae NCTC 418
}

\author{
Ed T. Buurman, $\nmid$ Gerald J. ten Voorde and M. Joost Teixeira de Mattos
}

Author for correspondence: Ed T. Buurman. Tel: +44 224 273178. Fax: + 44224273144.

Department of

Microbiology, E. C. Slater

Institute, Biocenter,

University of Amsterdam, PO

Box 20245, $1000 \mathrm{HE}$

Amsterdam, The

Netherlands
Periplasmic oxidation of glucose into gluconate and 2-ketogluconate in Klebsiella pneumoniae occurs via glucose dehydrogenase (GDH) and gluconate dehydrogenase (GaDH), respectively. Since, as is shown here, in the presence of glucose, gluconate and 2-ketogluconate are not further metabolized intracellularly the physiological function of this periplasmic route was studied. It was found that periplasmic oxidation of glucose could function as an alternative production route of ATP equivalents. Instantaneous activation of either GDH or GaDH reduced the rate of degradation of glucose via glycolysis and the tricarboxylic acid (TCA) cycle in vivo. Furthermore, aerobic, magnesium- and phosphate-limited chemostat cultures with glucose as the carbon source showed high GDH plus GaDH activities in contrast to nitrogenand sulphate-limited cultures. However, when fructose, which is not degraded by GDH, was the carbon source, specific oxygen consumption rates under these four conditions were essentially the same. The latter observation suggests that high transmembrane phosphate gradients which are supposedly present under phosphate-limited conditions do not cause high energetic demands due to futile cycling of phosphate ions. In addition, dissipation of the transmembrane phosphate gradient of phosphate-limited cells immediately increased the rate of intracellular glucose degradation. It is concluded that under phosphatelimited conditions (i) extensive futile cycling of phosphate ions is absent and (ii) low concentrations of phosphate ions limit intracellular degradation of glucose. Glyceraldehyde-3-phosphate dehydrogenase (GADPH) activities of cell-free extracts of glucose-grown cells harvested from aerobic chemostat cultures limited in various nutrients showed that at least a tenfold overcapacity in GAPDH activity was present under phosphate-limited conditions with respect to the steady-state carbon fluxes through this enzyme. The physiological significance of this adaptation and the possible role of GDH and GaDH are discussed.

Keywords: Klebsiella pneumoniae, periplasmic glucose oxidation, phosphate-limited growth, ATP

\section{INTRODUCTION}

Aerobic chemostat cultures of Klebsiella pneumoniae are able to convert glucose into gluconate and 2- ketogluconate (Neijssel \& Tempest, 1975) which, as will be shown here, are not further metabolized intracellularly in the presence of glucose. The production rate of these compounds strongly depends on the nature of the growthlimiting compound. Glucose-limited cultures do not produce gluconate or 2-ketogluconate whereas under potassium-, phosphate- and magnesium-limited conditions high rates are found. Low rates occur under sulphate- and nitrogen-limited conditions (Hommes et al., 1989b; Buurman et al., 1990). This has led to the proposition that increased energetic demands would invoke 
gluconate and 2-ketogluconate formation in order to increase the production of ATP equivalents (Hommes et al., 1985).

Two major lines of evidence support the view stated. above. First, it has been found that formation of gluconate: and 2-ketogluconate from glucose in K. pneumoniae occurs: by periplasmic oxidation of glucose via the pyrroloquinoline quinone (PQQ)-linked glucose dehydrogenase: $(\mathrm{GDH})($ Neijssel et al., 1983) and periplasmic oxidation of gluconate via the FAD-linked gluconate dehydrogenase $(\mathrm{GaDH})$ (Matsushita et al., 1982). The reducing equivalents formed in these reactions, $\mathrm{PQQH}_{2}$ and $\mathrm{FADH}$, are funneled into the respiratory chain (Beardmore-Gray \& Anthony, 1986; Matsushita et al., 1987). Therefore, it can be assumed that in K. pneumoniae periplasmic oxidation of glucose results in energy conservation as has been observed in other GDH-containing micro-organisms (Van Schie et al., 1985; Van Schie et al., 1987; Hardy et al., 1993). Secondly, under nitrogen-limited conditions high specific gluconate and 2 -ketogluconate production rates can be induced by the addition of 2,4-dinitrophenol (DNP) to the medium (Neijssel, 1977). This is ascribed to the dissipating effect of DNP on the protonmotive force $(\mathrm{PMF})$, thus causing energy wastage.

The occurrence of high GDH and $\mathrm{GaDH}$ activities in vivo under potassium-, magnesium- and phosphate-limited conditions has also been attributed to extensive energy wastage, caused by so-called futile cycling of the respective growth-limiting ions (Neijssel et al., 1990). Mulder et al. (1986) showed that in Escherichia coli under potassium-limited conditions 'energy spilling' occurs due to the simultaneous activity of multiple potassium transport systems with different affinities towards potassiurn (see, however, Buurman et al., 1992). Under phosphateand magnesium-linked conditions high affinity carriers for these respective substrates are synthesized in E. coli, in addition to constitutive low affinity transport systems (Rosenberg et al., 1977; Nelson \& Kennedy, 1972). Therefore, analogous to potassium-limited conditions, it has been proposed that futile cycling of phosphate and magnesium ions would result in increased energetic demands. In $K$. pneumoniae, increased production rates of ATP equivalents by periplasmic oxidation of glucose would compensate for this.

GDH holoenzyme is formed by binding of PQQ to GDH apoenzyme which requires the presence of divalent cations. This requirement has been used to manipulate in vivo GDH activity (Buurman et al., 1990). It was found that addition of $\mathrm{CaCl}_{2}$ to the medium of magnesiumlimited cultures increased GDH activity but simultaneously decreased the specific $\mathrm{CO}_{2}$ production rate, which apparently resulted from a lowered TCA cycle activity. In those experiments the presence of gluconate derepressed $\mathrm{GaDH}$ activity and caused conversion of gluconate into 2-ketogluconate. Therefore, it was not clear which of these two enzyme activities diminished $\mathrm{CO}, 2$ production rates. This present study was initiated to address this question. It became apparent that the decreased production of ATP equivalents by oxidation of reducing equivalents formed by TCA cycle activity could be sufficiently high to counteract the increased generation of ATP equivalents by oxidation of reducing equivalents formed during periplasmic oxidation. Hence, periplasmic oxidation of glucose could be an alternative energy conserving route rather than an additional one. Moreover, extensive wastage of energy due to futile cycling of phosphate ions under phosphate-limited conditions could not be demonstrated. An alternative function for periplasmic oxidation of glucose is presented in the case of phosphate-limited conditions.

\section{METHODS}

Organism and growth conditions. Klebsiella pneumoniae NCTC 418 was maintained by monthly subculture on tryptic meatdigest agar slopes. For nutrient-limited growth, simple salts media were used as specified by Evans et al. (1970). Carbonlimited media contained $27 \mathrm{mM}$ glucose or fructose, whereas carbon-excess media contained $165 \mathrm{mM}$ glucose, $165 \mathrm{mM}$ fructose or $55 \mathrm{mM}$ glucose plus $130 \mathrm{mM}$ sodium gluconate. In the latter case $\mathrm{H}_{2} \mathrm{SO}_{4}$ and $\mathrm{H}_{3} \mathrm{PO}_{4}$ replaced $\mathrm{Na}_{2} \mathrm{SO}_{4}$ and $\mathrm{NaH}_{2} \mathrm{PO}_{4}$ respectively, in order to prevent high medium $\mathrm{pH}$ value.

Under carbon-excess conditions, input concentrations were adjusted to obtain nitrogen-limited $\left(10 \mathrm{mM} \mathrm{NH}_{4} \mathrm{Cl}\right.$ or $10 \mathrm{mM}$ $\mathrm{NaNO}_{3}$ input), magnesium-limited $(62.5 \mu \mathrm{M} \mathrm{MgCl}$, and $1 \mathrm{mM}$ $\mathrm{CaCl}_{2}$ input), phosphate-limited $\left(0.5 \mathrm{mM} \mathrm{NaH}_{2} \mathrm{PO}_{4}\right.$ input $)$ or potassium-limited $(0.5 \mathrm{mM} \mathrm{KCl}$ input) conditions with a steadystate dry weight of approximately $1 \mathrm{~g} \mathrm{l}^{-1}$. Under nitrate-excess conditions $100 \mathrm{mM} \mathrm{NH}_{4} \mathrm{Cl}$ was replaced by $100 \mathrm{mM} \mathrm{NaNO}_{3}$ in the medium. All other growth conditions have been described in Buurman et al. (1990).

Analyses. Analyses of effluent gas and supernatants and determination of bacterial dry weight were carried out as described previously (Buurman et al., 1990). Cell-free extracts were prepared in distilled water according to Buurman et al. (1990); protein content of the extracts was determined by the biuret method using bovine serum albumin (Sigma) as a standard (Gornall et al., 1949). Glyceraldehyde-3-phosphate dehydrogenase (GAPDH) activities were determined according to Bergmeyer et al. (1974). Methylglyoxal (MGO) synthase activities were measured as the rate of disappearance of dihydroxyacetone phosphate in the absence of nucleotide cofactors, according to Hopper \& Cooper (1971) as modified by Streekstra (1990). Protein and RNA concentrations in the culture were determined according to Peterson (1977) using bovine serum albumin (Sigma) as a standard, and with the orcinol method as described by Herbert et al. (1971), respectively.

Calculations. In order to calculate the carbon flux through the TCA cycle, $q \mathrm{CO}_{2(\mathrm{TCA})}$, it has been assumed that $\mathrm{CO}_{2}$ formation via the pentose phosphate pathway is negligible (Fraenkel, 1987). From the well-established catabolic pathways it can be deduced that $\mathrm{CO}_{2}$ production is coupled to acetate production in the molar ratio $1: 1$ and to 2,3-butanediol and acetoin production in the ratio $2: 1$. On the other hand, net production of succinate and 2-oxoglutarate from glucose via phosphoenolpyruvate carboxylase involves fixation of $\mathrm{CO}_{2}(1: 1)$ that has been formed by the culture. Hence, $q \mathrm{CO}_{2(\mathrm{TCA})}$ can be calculated according to the equation:

$$
\begin{aligned}
q \mathrm{CO}_{2(\mathrm{TCA})}=q \mathrm{CO}_{2(\text { measured })} & +q_{2 \cdot \text { oxoglutarate }} \\
& +q_{\text {succinate }}-q_{\text {acetate }}-2 q_{\text {acetoin }}-2 q_{2,3 \text { butanediol }}
\end{aligned}
$$


Table 1. Effect of instantaneous and independent activation of GDH and GaDH on specific oxygen consumption and carbon dioxide production rates of $K$. pneumoniae

Growth was in magnesium-limited chemostat culture in the absence of $\mathrm{CaCl}_{2}$, and glucose $(165 \mathrm{mM})$ as carbon source $\left(D=0 \cdot 25 \pm 0 \cdot 01 \mathrm{~h}^{-1}, T=35 \pm 1^{\circ} \mathrm{C}, \mathrm{pH} 6 \cdot 0 \pm 0 \cdot 1,62 \cdot 5 \mu \mathrm{M} \mathrm{MgCl}_{2}\right)$. GDH and GaDH were acrivated by addition of $\mathrm{CaCl}_{2}(1 \mathrm{mM}$ final concentration) and sodium gluconate (15 $\mathrm{mM}$ final concentration), respectively. In order to derepress $\mathrm{GaDH}$ in steady state, sodium gluconate was added to the medium ( $1 \mathrm{mM}$ final concentration). Both rows show specific metabolic rates, $q$, in mmol ( $\mathrm{g} d r y$ $\mathrm{wt}^{-1} \mathrm{~h}^{\cdot}$, that are the average of two independent experiments. $\mathrm{SD}<10 \%$ of the mean.

\begin{tabular}{|ccccc|}
\hline & $\boldsymbol{\Delta} \boldsymbol{q}_{\text {gluconate }}$ & $\boldsymbol{\Delta} \boldsymbol{q}_{\text {2-ketogluconate }}$ & $\boldsymbol{\Delta} \boldsymbol{q} \mathrm{O}_{2}$ & $\boldsymbol{\Delta} \boldsymbol{q} \mathbf{C O}_{2}$ \\
\hline GDH activation & 27 & 0 & 13 & $-5 \cdot 1$ \\
GaDH activation & -27 & 28 & 10 & $-4 \cdot 4$ \\
\hline
\end{tabular}

For calculating GAPDH activities in vivo $\left(q \mathrm{C}_{3(\mathrm{GAPDH})}\right)$ it was assumed that biomass was formed from pyruvate and that all glucose not oxidized into gluconate or 2-ketogluconate was degraded via GAPDH exclusively (and not via the MGO bypass):

$q_{3(\text { GAPIH })}=\left(q_{\text {glucose }}-q_{\text {glueonate }}-q_{2 \text { - ketogluconate }}\right) 2$

\section{RESULTS}

K. pntumoniae was grown under aerobic, magnesiumlimited conditions in a chemostat with glucose as the carbon source. No $\mathrm{Ca}^{2+}$ ions were added to the medium. Due to the low concentration of divalent cations, GDH activits is not observed (Buurman et al., 1990). However, an instantaneous increase of the $\mathrm{Ca}^{2+}$ concentration in the culture vessel up to $1 \mathrm{mM}$ caused an immediate onset in the formation of gluconate. Concomitantly, a decrease in the specific $\mathrm{CO}_{2}$ production rate was observed (Table 1). In a second experiment, $1 \mathrm{mM}$ sodium gluconate was added $t o$ the medium in order to derepress $\mathrm{GaDH}$. Immediately sodium gluconate (final concentration, $15 \mathrm{mM}$ ) was added to these cultures, conversion of gluconate into 2-ketogluconate began and the specific $\mathrm{CO}_{2}$ production rate decreased (Table 1).

Specific acetate production rates $\left[0.5 \mathrm{mmol}(\mathrm{g} \text { dry } \mathrm{wt})^{-1}\right.$ $\mathrm{h}^{-1}$ in steady state] remained unchanged upon these additions and 2,3-butanediol was absent from the culture fluids (data not shown). From this, one has to conclude that the decreased specific $\mathrm{CO}_{2}$ production rates were due to lowered TCA cycle activity. Furthermore, in vivo GDH and $\mathrm{GaDH}$ activities (Table 1) were quite comparable to in vivo activities found under potassium-, phosphate- and magnesium-limited steady-state conditions (Tables 2 and $3)$. This indicates that under these conditions TCA cycle activity could be partially suppressed by high GDH and GaDH I activities.

Previously, Hommes et al. (1989a, b) suggested that oxidation of $\mathrm{PQQH}_{2}$ inhibited oxidation of $\mathrm{NADH}$ via the respiratory chain. The observed decrease in TCA cycle activity could be caused by this inhibitory effect on NADH oxidation. Hence, an additional drain on the internal NADH pool should overcome this inhibition and, thus, increase TCA cycle activity. With this aim, cells were grown with sodium nitrate as the nitrogen source, since it is assumed that assimilatory nitrate reduction in $K$. pneumoniae occurs aerobically via cytosolic, NADHdependent nitrate reductase and nitrite reductase (Stewart, 1988). The reduction of $1 \mathrm{~mol}$ nitric acid into ammonia requires $4 \mathrm{~mol} \mathrm{NADH}$. Assuming a biomass composition equivalent to the molecular formula $\mathrm{C}_{4} \mathrm{H}_{7} \mathrm{O}_{2} \mathrm{~N}$ (Herbert, 1976), specific biomass production rates of $2.5 \mathrm{mmol}(\mathrm{g}$ dry wt) ${ }^{-1} h^{-1}$ (i.e. specific growth rates of $0 \cdot 25 \mathrm{~h}^{-1}$ ) should cause additional NADH consumption of $10 \mathrm{mmol}(\mathrm{g} \mathrm{dry}$ $w t)^{-1} h^{-1}$. This would allow for an increase in the specific $\mathrm{CO}_{2}$ production rate via the TCA cycle of $5 \mathrm{mmol}(\mathrm{g}$ dry $\mathrm{wt})^{-1} \mathrm{~h}^{-1}$ as compared to cultures grown with ammonium chloride as the nitrogen source. This was found to be the case when cells were grown carbon-limited with sodium nitrate as the nitrogen source $\left(q \mathrm{CO}_{2(\mathrm{TCA})}\right.$, Table 2$)$. However, replacement of ammonium chloride by sodium nitrate barely affected $\mathrm{CO}_{2}$ production via the TCA cycle under potassium- or phosphate-limited conditions and only a minor increase was seen under nitrogen-limited conditions ( $q \mathrm{CO}_{2(\mathrm{TCA})}$, Table 2$)$.

In order to exclude the possibility that these differences were due to the nature of the growth-limiting component per se, aerobic, magnesium-limited conditions were tested both in the presence and the absence of $\mathrm{Ca}^{2+}$ ions. When $\mathrm{GDH}$ and $\mathrm{GaDH}$ activities were absent due to omission of $\mathrm{Ca}^{2+}$ ions from the medium, TCA cycle activity was again increased with $6 \mathrm{mmol}$ (g dry wt) $)^{-1} \mathrm{~h}^{-1}$ due to increased NADH requirement ( $q \mathrm{CO}_{2(\mathrm{TCA})}$, Table 3 ). However, when $1 \mathrm{mM}$ of $\mathrm{CaCl}_{2}$ was added to the medium $\mathrm{GDH}$ and $\mathrm{GaDH}$ became active but in this case the presence of sodium nitrate only caused a small increase in TCA cycle activity.

Finally, K. pneumoniae was grown under magnesiumlimited conditions in the absence of $\mathrm{Ca}^{2+}$ ions but in the presence of excess amounts of both glucose and sodium gluconate. Again, no increase in TCA cycle activity was observed when sodium nitrate was used as the nitrogen source. Clearly, high GaDH activity alone prevented an increase in TCA cycle activity. Remarkably, in the presence of excess concentrations of glucose, gluconate 
Table 2. Metabolic rates of variously limited cultures of $K$. pneumoniae

Growth was with either ammonium chloride or sodium nitrate as the nitrogen source $(D)=0.26 \pm 0.01 \mathrm{~h}^{-1}, \mathrm{~T}=35 \pm 1{ }^{\circ} \mathrm{C}, \mathrm{pH}=$ $6 \cdot 0 \pm 0 \cdot 1)$. Glucose was the carbon source. GaDH activity $\left(q_{\text {Gial }}\right)$ equals $q_{2 \text {-ketogluronate }}$; GDH activity $\left(q_{\text {GDH }}\right)=q_{\text {gluconate }}+q_{2-\text { ketogluconate }}$. Calculation of $q \mathrm{CO}_{2(T(\mathrm{~T})}$ was as described in Methods. Values are the average of 8-10 steady-state samples obtained from two independent chemostat runs. SD $<10 \%$ of the mean.

\begin{tabular}{|c|c|c|c|c|c|c|c|c|}
\hline \multirow{3}{*}{$\begin{array}{l}\text { Metabolite } \\
\text { Limited nutrient... } \\
\text { Nitrogen source... }\end{array}$} & \multicolumn{8}{|c|}{ Metabolic rate, $q\left[\mathrm{mmol}(\mathrm{g} \text { dry wt })^{-1} \mathrm{~h}^{-1}\right]$} \\
\hline & \multicolumn{2}{|c|}{ Carbon } & \multicolumn{2}{|c|}{ Nitrogen } & \multicolumn{2}{|c|}{ Phosphate } & \multicolumn{2}{|c|}{ Potassium } \\
\hline & $\mathrm{NH}_{4} \mathrm{Cl}$ & $\mathrm{NaNO}_{3}$ & $\mathrm{NH}_{4} \mathrm{Cl}$ & $\mathrm{NaNO}_{3}$ & $\mathrm{NH}_{4} \mathrm{Cl}$ & $\mathrm{NaNO}_{3}$ & $\mathrm{NH}_{4} \mathrm{Cl}$ & $\mathrm{NaNO}_{3}$ \\
\hline Glucose & $3 \cdot 1$ & $3 \cdot 9$ & $9 \cdot 5$ & 13 & 19 & 28 & 36 & 30 \\
\hline Gluconate & 0 & 0 & $0 \cdot 8$ & $1 \cdot 3$ & 4.9 & 12 & $8 \cdot 2$ & 11 \\
\hline 2-Ketogluconate & 0 & 0 & $3 \cdot 2$ & $4 \cdot 5$ & 12 & 13 & 17 & 10 \\
\hline $\mathrm{CO}_{2}$ & $7 \cdot 6$ & 13 & $9 \cdot 1$ & 12 & $8 \cdot 1$ & $9 \cdot 7$ & 16 & 12 \\
\hline Biomass & $2 \cdot 5$ & $2 \cdot 6$ & $2 \cdot 6$ & $2 \cdot 6$ & $2 \cdot 6$ & $2 \cdot 5$ & $2 \cdot 6$ & $2 \cdot 6$ \\
\hline 2-Oxoglutarate & 0 & 0 & $1 \cdot 6$ & $1 \cdot 5$ & $0 \cdot 2$ & 0.5 & $0 \cdot 9$ & $1 \cdot 3$ \\
\hline Pyruvate & 0 & 0 & 1.9 & $3 \cdot 8$ & $0 \cdot 1$ & $0 \cdot 3$ & $1 \cdot 7$ & $3 \cdot 1$ \\
\hline Acetate & 0 & 0 & 0 & 0 & 0 & $0 \cdot 7$ & $1 \cdot 8$ & $1 \cdot 4$ \\
\hline Succinate & 0 & 0 & 0 & 0 & 0 & 0 & $0 \cdot 2$ & $0 \cdot 1$ \\
\hline Acetoin & 0 & 0 & 0 & 0 & 0 & 0 & $0 \cdot 6$ & $0 \cdot 3$ \\
\hline 2,3-Butanediol & 0 & 0 & 0 & 0 & 0 & 0 & 1.5 & $0 \cdot 3$ \\
\hline $\mathrm{O}_{2}$ & 6.7 & $8 \cdot 3$ & 14 & 14 & 19 & 18 & 28 & 19 \\
\hline C recovery $(\%)$ & 95 & 98 & 100 & 98 & 106 & 98 & 93 & 94 \\
\hline $\mathrm{CO}_{2(\mathrm{~T}(\mathrm{~A})}$ & $7 \cdot 6$ & 13 & 11 & 14 & $8 \cdot 3$ & $9 \cdot 5$ & 11 & 11 \\
\hline$q_{(\mathrm{irHH}}+q_{\mathrm{Ga \textrm {DH }}}$ & 0 & 0 & $7 \cdot 2$ & 10 & 29 & 38 & 42 & 31 \\
\hline
\end{tabular}

Table 3. Metabolic rates of aerobic, magnesium-limited cultures of $K$. pneumoniae

Rates were measured in the presence and absence of GDH and ( $\mathrm{GaDH}$ activities, with cultures grown with either ammonium chloride or sodium nitrate as the nitrogen source $\left(D=0 \cdot 26 \pm 0 \cdot 01 \mathrm{~h}^{-1}, T=35 \pm 1{ }^{\circ} \mathrm{C}, 62 \cdot 5 \mu \mathrm{M} \mathrm{MgCl}, \mathrm{pH}=6 \cdot 0 \pm 0 \cdot 1\right)$. Carbon sources were either glucose $(165 \mathrm{mM})$ or glucose $(55 \mathrm{mM})$ plus sodium gluconate $(130 \mathrm{mM}) . \mathrm{GaDH}$ activity $\left(q_{\mathrm{GaDH}}\right)=q_{2 \text { ketogluconate }}$; (GDH activity $\left(q_{\mathrm{GinH}}\right)$ (only present when $\mathrm{CaCl}_{2}$ is added) $=q_{\mathrm{glu} \text { (onate }}+q_{2 \text { ketogluronate. }}$. Calculation of $q \mathrm{CO}_{2(\mathrm{TCA})}$ was as described in Methods. Values are the average of 8-10 steady-state samples obtained from two independent chemostat runs. SD $<10 \%$ of the mean.

\begin{tabular}{|c|c|c|c|c|c|c|c|}
\hline \multirow[t]{3}{*}{ Metabolite } & \multirow{3}{*}{$\begin{array}{l}\text { Carbon source... } \\
\text { Input } \mathrm{CaCl}_{2} \ldots \\
\text { Nitrogen source... }\end{array}$} & \multicolumn{6}{|c|}{ Metabolic rate, $q\left[\mathrm{mmol}(\mathrm{g} \text { dry } w \mathrm{t})^{-1} \mathrm{~h}^{-1}\right]$} \\
\hline & & \multicolumn{2}{|c|}{$\begin{array}{l}\text { Glucose } \\
0 \mathrm{mM}\end{array}$} & \multicolumn{2}{|c|}{$\begin{array}{l}\text { Glucose } \\
1 \mathrm{mM}\end{array}$} & \multicolumn{2}{|c|}{$\begin{array}{c}\text { Glucose }+ \text { sodium } \\
\text { gluconate } \\
0 \mathrm{mM}\end{array}$} \\
\hline & & $\mathrm{NH}_{4} \mathrm{Cl}$ & $\mathrm{NaNO}_{3}$ & $\mathrm{NH}_{4} \mathrm{Cl}$ & $\mathrm{NaNO}_{3}$ & $\mathrm{NH}_{4} \mathrm{Cl}$ & $\mathrm{NaNO}_{3}$ \\
\hline Glucose & & $7 \cdot 8$ & $8 \cdot 6$ & 31 & 29 & $9 \cdot 6$ & $8 \cdot 8$ \\
\hline Gluconate & & 0 & 0 & $7 \cdot 5$ & $6 \cdot 7$ & -35 & -34 \\
\hline 2-Ketogluconate & & 0 & 0 & 21 & 18 & 37 & 35 \\
\hline $\mathrm{CO}_{2}$ & & 16 & 21 & 10 & 11 & 20 & 15 \\
\hline Biomass & & $2 \cdot 6$ & $2 \cdot 5$ & $2 \cdot 6$ & $2 \cdot 6$ & $2 \cdot 6$ & $2 \cdot 7$ \\
\hline 2-Oxoglutarate & & $1 \cdot 3$ & $0 \cdot 9$ & 0.5 & $0 \cdot 7$ & $0 \cdot 6$ & $0 \cdot 9$ \\
\hline Pyruvate & & $0 \cdot 7$ & 0.8 & $0 \cdot 3$ & $1 \cdot 0$ & $0 \cdot 6$ & $1 \cdot 1$ \\
\hline Acetate & & $1 \cdot 5$ & $1 \cdot 3$ & $1 \cdot 2$ & $1 \cdot 3$ & $1 \cdot 6$ & $1 \cdot 4$ \\
\hline Succinate & & $0 \cdot 4$ & $0 \cdot 5$ & $0 \cdot 3$ & $0 \cdot 4$ & $0 \cdot 4$ & $0 \cdot 3$ \\
\hline Acetoin & & 0 & 0 & 0 & 0 & 0.7 & 0 \\
\hline 2,3-Butanediol & & $1 \cdot 5$ & 0.9 & $0 \cdot 2$ & 0 & $2 \cdot 0$ & $0 \cdot 3$ \\
\hline $\mathrm{O}_{2}$ & & 16 & 17 & 27 & 24 & 26 & 22 \\
\hline C-recovery $(\%)$ & & 97 & 89 & 107 & 104 & 102 & 97 \\
\hline$C)_{2(\mathrm{TCA})}$ & & 13 & 19 & $9 \cdot 2$ & 11 & 14 & 14 \\
\hline$q_{\mathrm{GDH}}+q_{\mathrm{GaDH}}$ & & 0 & 0 & 50 & 43 & 36 & 35 \\
\hline
\end{tabular}


was converted to 2-ketogluconate only and did not serve as a carbon source (Table 3 ). It can be concluded that the physiological role of periplasmic oxidation of glucose is the generation of reducing equivalents. This has led to the suggestion that periplasmic oxidation of glucose serves as an additional energy conserving system that is active under conditions which cause increased energetic demands (Hommes et al., 1985). However, our data suggest that an increased rate of generation of reducing equivalents via $\mathrm{GDH}$ and $\mathrm{GaDH}$ activities is accompanied by a decreased rate via TCA cycle activity.

Therefore, the question of whether oxidation of glucose via $G D H$ and $G a D H$ causes a net increase in the specific production rate of ATP equivalents was investigated by comparing the energetic demands of $K$. pneumoniae grown under kerobic conditions with various nutrients limited and with fructose as the carbon and energy source $\left(D=0.24 \pm 0.01 \mathrm{~h}^{-1}, \quad T=35 \pm 1{ }^{\circ} \mathrm{C}, \quad \mathrm{pH}=6 \cdot 0 \pm 0 \cdot 1\right)$. Since fructose is not a substrate for $\mathrm{GDH}$ (Ameyama et al., 1986), degradation of fructose occurs solely via glycolysis and the TCA cycle, independent of the nature of the growth-limiting nutrient. Under these conditions formation of overflow metabolites did not occur (data not shown). Under fructose-limited conditions specific oxygen consumption rates were virtually identical to those observed under glucose-limited conditions. Potassiumlimited growth conditions caused the highest specific oxygen consumption rates $\left[18 \mathrm{mmol}(\mathrm{g} \mathrm{dry} \mathrm{wt})^{-1} \mathrm{~h}^{-1}\right]$, whereas the specific oxygen consumption rates of magnesium-, phosphate-, nitrogen- and sulphate-limited cultures all ranged between 11 and $13 \mathrm{mmol}(\mathrm{g} \mathrm{dry} \mathrm{wt})^{-1}$ $\mathrm{h}^{-1}$. From this observation it can be concluded that if specific oxygen consumption rates are indicative of the energy requirement, the energetic demands of the latter four growth conditions are essentially identical. Yet activity of the periplasmic glucose oxidation system is in vivo widely different for these conditions (Tables 2 and 3; Hommes et al., 1989b).

The above-mentioned results suggest that periplasmic oxidation of glucose does not result in increased production rates of ATP equivalents. However, under phosphate-limited conditions increased production rates of ATP equivalents would be required if extensive energy spilling due to futile cycling of phosphate ions were to occur. In order to obtain evidence for the presence of this futile cycle, $K$. pneumoniae was grown under aerobic, phosphate-limited conditions in chemostat culture with glucose as the carbon and energy source. When the culture was in a steady state the extracellular concentration of phosphate ions was instantaneously increased to $5 \mathrm{mM}$. Immediately, both oxygen consumption (Fig. 1a) and carbon dioxide production (data not shown) increased. As virtually no other products were excreted, the presence of phosphate ions must have increased glucose catabolism via glicolysis and the TCA cycle. At the same time the specific growth rate, as measured by protein and RNA concentration, optical density and dry weight, increased from $0.24 \mathrm{~h}^{-1}$ to $0.7 \mathrm{~h}^{-1}$ (data not shown).

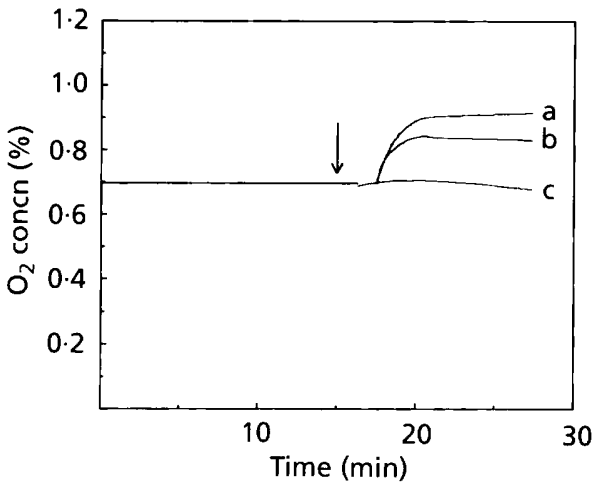

Fig. 1. Typical recorder tracings of differences in oxygen concentrations between influent and effluent gas of phosphate-limited chemostat cultures of $K$. pneumoniae due to oxygen consumption $\left(D=0.24 \pm 0.01 \mathrm{~h}^{-1}, \mathrm{pH}=6.0 \pm 0.1, T=\right.$ $35 \pm 1{ }^{\circ} \mathrm{C}, 165 \mathrm{mM}$ glucose). Influent gas contained $21 \%(\mathrm{v} / \mathrm{v})$ oxygen. At $t=15 \mathrm{~min}$ the phosphate concentration was instantaneously increased to $5 \mathrm{mM}$ (arrow). (a) No addition prior to phosphate pulse; (b) CAP (100 $\left.\mathrm{mg} \mathrm{l}^{-1}, t=5 \mathrm{~min}\right)$ plus DNP (0.1 mM, $t=9 \mathrm{~min})$ added; (c) CAP (100 $\left.\mathrm{mg} \mathrm{l}^{-1}, t=7 \mathrm{~min}\right)$ added. During the experiments addition of medium to the culture continued. Each experiment was performed at least twice. Dead volume in both chemostat and tubing to the gas analyser caused approximately 2 min delay in monitoring changes in oxygen concentrations.

In order to determine whether the increase in growth rate was essential for elevated oxygen consumption, in the next experiment the increase of the growth rate was prevented by the addition of chloramphenicol (CAP) prior to the phosphate pulse. Under these conditions there was no increase in growth rate and oxygen consumption did not change (Fig. 1c). Apparently, accelerated anabolism, which is essentially an energy sink, was required for an increased rate of catabolism. Either the presence of phosphate ions resulted in an increased anabolic rate (and the elevated rate of catabolism was just a consequence of this increased growth rate), or the primary response was a stimulation of catabolism. However, when addition of CAP was followed by a pulse of DNP (final concentration of $0.1 \mathrm{mM}$ ) oxygen consumption and carbon dioxide production remained unchanged, but subsequent addition of phosphate ions resulted again in a higher rate of catabolism (Fig. 1b). Thus, the acceleration of catabolism depended on the presence of both phosphate ions and an energy sink.

The demand for phosphate ions for the expression of catabolic overcapacity suggests that low intracellular concentrations of phosphate ions limit the intracellular degradation of glucose to a great extent. This may occur at the level of the membrane-bound ATP synthase. If this were the case, however, one would expect the specific oxygen consumption rate to increase by the addition of DNP. Since this did not occur (Fig. 1c; $t=9 \mathrm{~min}$ ), it was more likely that the low intracellular phosphate pool limited the rate of GAPDH, the only phosphatedependent activity in glycolysis. From Table 4 it can be seen that phosphate-limited conditions caused signifi- 
Table 4. Steady-state GAPDH and MGO synthase activities in variously-limited aerobic chemostat cultures of $K$. pneumoniae

Glucose was the carbon source $\left(D=0 \cdot 25 \pm 0 \cdot 01 \mathrm{~h}^{-1}, T=\right.$ $\left.35 \pm 1{ }^{\circ} \mathrm{C}, \mathrm{pH}=6 \cdot 0 \pm 0 \cdot 1\right)$. In vitro $\mathrm{GAPDH}$ activities are given in $\mu \mathrm{mol} \mathrm{NAD}$ reduced $\mathrm{min}^{-1}$ (mg protein $)^{-1}$ and in vitro $\mathrm{MGO}$ synthase activities are given in $\mu \mathrm{mol}$ DHAP consumed $\mathrm{min}^{-1}$ ( $\mathrm{mg}$ protein $)^{-1}$; the number of determinations is given in parentheses. In wivo GAPDH activities, in mmol $_{3}$ (gdry $\left.\mathrm{wt}\right)^{-1} \mathrm{~h}^{-1}$, have been calculated from metabolic rates where indicated, as described in Methods.

\begin{tabular}{|c|c|c|c|}
\hline \multirow[t]{3}{*}{ Limited nutrient } & \multicolumn{3}{|c|}{ Activity } \\
\hline & \multicolumn{2}{|c|}{ GAPDH } & \multirow{2}{*}{$\begin{array}{c}\text { MGO } \\
\text { synthase } \\
\text { in vitro }\end{array}$} \\
\hline & in vitro & in vivo & \\
\hline Glucose & $0.53 \pm 0.05(5)$ & $6 \cdot 2$ & $0 \cdot 34 \pm 0 \cdot 12(5)$ \\
\hline Sulphate & $0.63 \pm 0.25(4)$ & $17^{*}$ & $0.24 \pm 0.07(2)$ \\
\hline Magnesium & $0 \cdot 67 \pm 0.19(6)$ & $5 \cdot 0$ & $0 \cdot 20 \pm 0.07(2)$ \\
\hline Potassium & $1 \cdot 04 \pm 0.05(4)$ & 22 & $0.23 \pm 0.06(4)$ \\
\hline Nitrogen & $0.94 \pm 0.17(4)$ & 11 & $0.49 \pm 0.12(4)$ \\
\hline Phosphate & $1 \cdot 50 \pm 0.23(4)$ & $4 \cdot 2$ & $0.57 \pm 0.27(3)$ \\
\hline
\end{tabular}

* Value taken from Hommes et al. (1989b).

cantly higher GAPDH activity in vitro whereas activity in vivo was the lowest.

\section{DISCUSSION}

The strict requirement for divalent cations of the GDH holoenzyme of $K$. pneumoniae was used to study in vivo the separate effects of GDH and GaDH on intracellular glucose degradation. Hommes et al. (1985) proposed that both enzymes function as an additional energy conserving system which would increase the production of ATP equivalents when the energetic demands of the cells would become high. Our results indicate that activation of either enzyme resulted in lowered degradation rates via the TCA cycle (Table 1). Therefore, the net effect of activation of periplasmic oxidation of glucose on the specific production rate of ATP equivalents depends on the efficiencies with which oxidation of $\mathrm{PQQH}_{2}, \mathrm{FADH}$ and NADH contribute to maintenance of the PMF. Nitrogen-, sulphate-, phosphate- and magnesium-limited cultures with fructose as the carbon and energy source showed comparable specific oxygen consumption rates, whereas the GDH and $\mathrm{GaDH}$ activities in similarly glucose-grown cultures were quite different from one another (Tables 2 and 3; Hommes et al., 1989b). If these oxygen consumption rates are indicative of the energetic demands under the respective conditions, one has to conclude that activation of GDH and $\mathrm{GaDH}$ does no result in increased production rates of ATP equivalents. Therefore we propose that GDH and GaDH function as; an alternative energy conserving system rather than art additional one.
The use of sodium nitrate to increase NADH consumption did not increase TCA cycle activity in the presence of high specific gluconate plus 2-ketogluconate production rates (Tables 2 and 3). Therefore it seems unlikely that the observed reduction in TCA cycle activity upon instantaneous activation of periplasmic oxidation of glucose (Table 1) was caused by an inhibitory effect of oxidation of $\mathrm{PQQH}_{2}$ and FADH on NADH oxidation. In contrast to NAD, which can be regenerated independent of the respiratory chain (for example via pyruvate conversion into 2,3-butanediol), oxidation of the reduced flavin nucleotides formed by the oxidation of succinate must occur via the respiratory chain. In E. coli these electrons enter the respiratory chain at the level of the ubiquinone pool to which electrons from the reduced cofactors of GDH and $\mathrm{GaDH}, \mathrm{PQQH}_{2}$ and FADH respectively, are also donated (Beardmore-Gray \& Anthony, 1986; Matsushita et al., 1987). When a similar situation exists in K. pneumoniae this would suggest that a high activity of GDH and GaDH impeded oxidation of reducing equivalents formed via succinate dehydrogenase and thereby inhibited TCA cycle activity. Of course, the opposite could also be true: low succinate dehydrogenase activities, due to an inhibitory effect of low concentrations of the growth-limiting compound on intracellular metabolism, could permit high oxidation rates of $\mathrm{PQQH}{ }_{2}$ and FADH and thus high GDH and $\mathrm{GaDH}$ activities in vivo.

From the literature on phosphate ion content $[0.02 \mathrm{mmol}$ (g dry wt $)^{-1}$; Aiking et al., 1984], cytoplasmic volume [3 ml (g dry wt) ${ }^{-1}$; Meury \& Kepes, 1981] and affinity of a high affinity phosphate carrier $(0.25 \mu \mathrm{M}$; Rao \& Torriani, 1990), it can be deduced that a $10^{4}$-fold concentration gradient of phosphate ions across the cytoplasmic membrane of phosphate-limited cells could occur. This high transmembrane gradient of phosphate ions could cause leakage of phosphate ions into the extracellular fluids. Subsequent energy-driven re-uptake of phosphate ions could cause increased oxygen consumption rates. Our results suggest the absence of futile cycling of phosphate ions under phosphate-limited conditions. Dissipation of the transmembrane phosphate gradient of a phosphate-limited culture of $K$. pneumoniae led to an instantaneously increased oxygen consumption (Fig. 1a) and carbon dioxide production. This increase was found to depend on two factors: a stimulation of intracellular glucose degradation by the increased phosphate concentration and the presence of an energy sink were both essential. We propose that the stimulation by phosphate ions of glucose metabolism stems from the relief of GAPDH being rate-limiting due to low concentrations of phosphate ions in the cell. First, addition of phosphate stimulated intracellular glucose degradation but not periplasmic oxidation. Secondly, the flux in vilo through GAPDH was found to be among the lowest of the various nutrient-limited conditions tested whereas the activity in vitro was the highest observed (Table 4). Apparently, under phosphate-limited conditions there is a considerable overcapacity in GAPDH activity present. 
It has been suggested that under phosphate-limited conditions degradation of glyceraldehyde 3-phosphate could occur via the MGO bypass (Cooper, 1984). In cellfree extracts MGO synthase activities were indeed found (Table 4). This implies that the relatively low GAPDH activity in vivo could even be overestimated under phosphate-limited conditions. Furthermore, since degradation of glyceraldehyde 3-phosphate via the MGO bypass does not involve substrate-level phosphorylation, the efficiency of glucose breakdown would be lowered in terms of moles of ATP equivalents synthesized per mol glucose degraded (Cooper, 1984).

From our results it seems justified to conclude that phosphate-limited conditions lower the intracellular phosphate pool to the extent that the flux in vivo through GAPDH becomes limited by the availability of phosphate ions. The lowered rate and (when part of it would occur via the MGO bypass) the decreased efficiency of degradation of glyceraldehyde 3-phosphate could cause a low energy charge in the cell and/or a low PMF and, as a result, activate periplasmic oxidation. This would also explain that addition of the uncoupler DNP to nitrogenlimited cultures activated periplasmic oxidation of glucose (Neijssel, 1977). Subsequently, generation of ATP equivalents via $G D H$ and $G a D H$ could allow for a lower flux via GAPDH and, thus, a further lowering of the intracellular phosphate pool. This means that lower specific phosphate uptake rates would be required or, in other words, cells could grow faster at a given extracellular concentration of phosphate ions. In this way it can be understood that under phosphate-limited conditions activation of periplasmic oxidation of glucose in K. pneumoniae can provide a competitive advantage to the organism without resulting in a net increase in production rate of ATP equivalents.

\section{REFERENCES}

Aiking, H., Stijnman, A., Van Garderen, C., Van Heerikhuizen, $\mathbf{H}$. \& Van't Riet, J. (1984). Inorganic phosphate accumulation and cadmium detoxification in Klebsiella aerogenes NCTC 418 growing in continuous culture. Appl Environ Microbiol 47, 374-377.

Ameyama, M., Nonobe, M., Shinagawa, E., Matsushita, K., Takimoto, K. \& Adachi, O. (1986). Purification and characterization of the quinoprotein D-glucose dehydrogenase apoenzyme from Escherictiua inli. Agric Biol Chem 50, 49-57.

Beardmore-Gray, M. \& Anthony, C. (1986). The oxidation of glucose by Acinetobacter calcoacticus: interaction of the quinoprotein glucose dehydrogenase with the electron transport chain. J Gen Microbioi 132, 1257-1268.

Bergmeyer, H. U., Gawehn, K. \& Grassl, M. (1974). Enzyme als biochemische Reagentien. In Methoden der envymatischen. Analyse, vol. I, pp. 454557 . Edited by H. U. Bergmeyer. Weinheim Germany: Verlag (hemie.

Buurman, E. T., Boiardi, J. L., Teixeira de Mattos, M. J. \& Neijssel, O. M. (1990). The role of magnesium and calcium ions in the glucose dehydrogenase activity of Klebsiella pneumoniae NCTC 418. Arch Mirobiol 153, 502-505.

Buurman, E. T., Teixeira de Mattos, M. J. \& Neijssel, O. M. (1992). Futile cycling of potassium and ammonium ions in Eschericbia coli.
In Alcali Cation Transport in Procaryotes, pp. 411-426. Edited by E. P. Bakker. Boca Raton, FL: CRC Press.

Cooper, R. A. (1984). Metabolism of methylglyoxal in microorganisms. Ann Rev Microbiol 38, 49-68.

Evans, C. G. T., Herbert, D. \& Tempest, D. W. (1970). The continuous cultivation of micro-organisms. II. Construction of a chemostat. In Methods in Microbiology, vol. 2, pp. 277-327. Edited by J. R. Norris \& D. W. Ribbons. London \& New York: Academic Press.

Fraenkel, D. G. (1987). Glycolysis, pentose-phosphate pathway, and Entner-Doudoroff pathway. In Escherichia coli and Salmonella typhimurium, vol. 1, pp. 142-150. Edited by F. C. Neidhardt and others. Washington, DC: American Society for Microbiology.

Gornall, A. G., Bardawill, C. J. \& David, M. A. (1949). Determination of serum proteins by means of the biuret reaction. $J$ Biol Chem 177, 751-766.

Hardy, G. P. M. A., Teixeira de Mattos, M. J. \& Neijssel, O. M. (1993). Energy conservation by pyrroloquinoline quinone-linked xylose oxidation in Pseudomonas putida NCTC 10936 during carbonlimited growth in chemostat culture. FEMS Microbiol Lett 107, $107-110$.

Herbert, D. (1976). Stoicheiometric aspects of microbial growth. In Continuous Culture. 6. Applications and New Fields, pp. 1-30. Edited by A. C. R. Dean, D. C. Ellwood, C. G. T. Evans \& J. Melling. Chichester: Ellis Horwood.

Herbert, D., Phipps, P. J. \& Strange, R. E. (1971). Chemical analysis of microbial cells. Methods in Microbiology 5B, 209-344.

Hommes, R. W. J., Van Hell, B., Postma, P. W., Neijssel, O. M. \& Tempest, D.W. (1985). The functional significance of glucose dehydrogenase in Klebsiella aerogenes. Arcb Microbiol 143, 163-168.

Hommes, R. W. J., Herman, P. T. D., Postma, P. W., Tempest, D. W. \& Neijssel, O. M. (1989a). The separate roles of PQQ and apoenzyme syntheses in the regulation of glucose dehydrogenase activity in Klebsiella pneumoniae NCTC 418. Arch Microbiol 151, 257-260.

Hommes, R. W. J., Postma, P. W., Neijssel, O. M. \& Tempest, D. $\mathbf{W}$. (1989b). The influence of culture $\mathrm{pH}$ value on the direct glucose oxidative pathway in Klebsiella pneumoniae NCTC 418. Arch Microbiol 151, 261-267.

Hopper, D. J. \& Cooper, R. A. (1971). The regulation of Escherichia coli methylglyoxal synthase; A new control site in glycolysis? FEBS Lett 13, 213-216.

Matsushita, K., Shinagawa, E. \& Ameyama, M. (1982). DGluconate dehydrogenase from bacteria, 2-keto-D-gluconate-yielding, membrane bound. Metbods Enzymol 89, 187-193.

Matsushita, K., Nonobe, M., Shinagawa, E., Adachi, O. \& Ameyama, M. (1987). Reconstitution of a pyrroloquinoline quinone-dependent $\mathrm{D}$-glucose oxidase respiratory chain of Escherichia coli with cytochrome o-oxidase. J Bacteriol 169, 205-209.

Meury, J. \& Kepes, A. (1981). The regulation of potassium fluxes for the adjustment and maintenance of potassium levels in Escherichia coli. Eur J Biocbem 119, 165-170.

Mulder, M. M., Teixeira de Mattos, M. J., Postma, P. W. \& Van Dam, K. (1986). Energetic consequences of multiple $\mathrm{K}^{+}$uptake systems. Biochim Biophys Acta 851, 223-228.

Neijssel, O. M. (1977). The effect of 2,4-dinitrophenol on the growth of Klebsiella aerogenes NCTC 418 in aerobic chemostat cultures. FEMS Microbiol Lett 1, 47-50.

Neijssel, O. M., Buurman, E. T. \& Teixeira de Mattos, M. J. (1990). The role of futile cycles in the energetics of bacterial growth. Biocbim Biophys Acta 1018, 252-255. 
Neijssel, O. M. \& Tempest, D. W. (1975). Production of gluconic acid and 2-ketogluconic acid by Klebsiella aerogenes. Arch Microbiol 105, 183-185.

Neijssel, O. M., Tempest, D. W., Postma, P. W., Duine, J. A. \& Frank Jzn, J. (1983). Glucose metabolism by $\mathrm{K}^{+}$-limited Klebsieila aerogenes: evidence for the involvement of a quinoprotein glucose dehydrogenase. FEMS Microbiol Lett 20, 35-39.

Nelson, D. L. \& Kennedy, E. P. (1972). Transport of magnesium by a repressible and a non-repressible system in Escherichia coli. Proc Natl Acad Sci US A 69, 1091-1093.

Peterson, G. L. (1977). A simplification of the protein assay method of Lowry et al. which is more generally applicable. Anal Biochem 83, 346-356.

Rao, N. N. \& Torriani, A. (1990). Molecular aspects of phosphate transport in Eschericbia coli. Mol Microbiol 4, 1083-1090.

Rosenberg, H., Gerdes, R. G. \& Chegwidden, K. (1977). Two systems for the uptake of phosphate in Escherichia coli. J Bacteriol 131, 505-511.
Stewart, V. (1988). Nitrate respiration in relation to facultative metabolism in Enterobacteria. Microbiol Rev 52, 190-232.

Streekstra, H. (1990). Metabolic uncoupling in anaerobic Klebsiella pneumoniae. $\mathrm{PhD}$ thesis, University of Amsterdam, 'The Netherlands.

Van Schie, B. J., Hellingwerf, K. J., Van Dijken, J. P., Elferink, M. G. L., Van Dijl, J. M., Kuenen, J. G. \& Konings, W. N. (1985). Energy transduction by electron transfer via a pyrroloquinoline quinone-dependent glucose dehydrogenase in Escherichia coli, Pseudomonas aeruginosa, and Acinetobacter calcoaceticus (var. lwoffi). J Bacteriol 136, 493-499.

Van Schie, B. J., Rouwenhorst, R. J., De Bont, J. A. M., Van Dijken, J. P. \& Kuenen, J. G. (1987). An in vivo analysis of the energetics of aldose oxidation by Acinetobacter calcoaceticus. Appl Microbiol Biotechnol 26, 560-567.

Received 21 March 1994; Accepted 26 April 1994. 